\title{
Chickpea Hybridization Using In Vitro Techniques
}

\author{
Nalini Mallikarjuna and Fred J. Muehlbauer
}

\begin{abstract}
Tissue culture techniques play an important role in the utilization of wild Cicer species for the improvement of cultivated chickpea. Utilization of wild Cicer species has become essential as a series of evolutionary bottlenecks have narrowed the genetic base of chickpea, thus making it susceptible to a range of diseases and pests. Crosses with wild Cicer can broaden its genetic base and introduce useful traits. Except for two wild species, none of the other Cicer species are cross-compatible. To use a range of Cicer species for the improvement of chickpea, embryo rescue and tissue culture techniques are necessary. The success of the cross with incompatible species depended on a range of techniques including the application of growth regulators to pollinated pistils and saving aborting embryos in vitro. Further, the chances of successful transfer of hybrid shoots to soil are greater if the hybrid shoots are grafted to chickpea stocks.
\end{abstract}

Key words: Chickpea, Cicer species, Cleft graft, Embryo rescue, Growth regulators, Incompatibility

\section{Introduction}

Chickpea is one of the Neolithic crops and in cultivation for more than 10,000 years. It is an important source of staple protein source in many Asian, African, and Middle Eastern countries. It has one of the highest nutritional compositions of any dry edible legume. Chickpeas' average nutritional composition is $23 \%$ protein, $64 \%$ total carbohydrates, $47 \%$ starch, $5 \%$ fat, $6 \%$ crude fiber, $6 \%$ soluble sugar, and $3 \%$ ash (1). Chickpea protein digestibility is the highest among the dry edible legumes. Like other food legumes, chickpea is rich in the essential amino acid lysine. Chickpeas are unique in moderating the rise in plasma glucose after meals and help control diabetes. Chickpea is high in phosphorus (343 mg/100 g), calcium (186 mg/100 g), magnesium (141 mg/100 g), iron (7 mg/100 g), and zinc (3 mg/100 g) (1). The seeds contain carotenoids such as beta-carotene, 
cryptoxanthin, lutein, and zeaxanthin in amounts above the engineered beta-carotene-containing "golden rice" level (2). Nutritional benefits of chickpea could be one of the reasons for the rise of civilization in the Fertile Crescent of Mesopotamia. According to Kerem et al. (3), chickpea contains higher amounts of tryptophan, which is a precursor of the neurotransmitter serotonin, which affects brain function and human behavior. Hence, higher amounts of tryptophan might have played a major role in selecting chickpea during human expansion as tryptophan promotes birth rates and accelerated growth in humans and animals.

Chickpea has undergone a series of evolutionary bottlenecks, which has narrowed its genetic base, and hence is susceptible to more than 47 diseases (4) and 54 insect pests (5). Sources of resistance to the desired level are not present in the cultivated gene pool and this opens up avenues to look for resistant sources in the related wild species germplasm. Chickpea has 34 accessions of perennial Cicer and 8 accessions of annual Cicer species. In spite of this immense wealth of wild species germplasm, only two wild Cicer species are crossable with the cultigen and are amenable to gene transfer through wide crosses. The remaining 6 annual and 34 perennial Cicer species are not available for chickpea improvement.

The proven method of bringing in large variation into chickpea is through wide crosses, as the other methods of somaclonal variation and mutation breeding are cumbersome, time consuming, and unpredictable. Compatible wild species of chickpea have played an important role in broadening the genetic base through the introduction of desirable traits such as Ascochyta blight resistance (6), Botrytis gray mold resistance (7), Helicoverpa armigera resistance (8), nematode resistance (9), and high yield (10).

The genus Cicer is classified into three gene pools based on its crossability with cultigens. Based on their crossability with cultivated species, wild species, both annual and perennial, have been grouped. Using the classification proposed by Harlan and de Wet (11), a modification of the classification is proposed. Although the modification does not deviate much from the previously proposed gene pools for chickpea, the secondary gene pool is strengthened by the placement of Cicer reticulatum. The proposed classification is similar to the recent classification proposed by van der Maesen et al. (12). The primary gene pool consists of cultivated species and land races. The secondary gene pool consists of the progenitor species, C. reticulatum and C. echinospermum, a species that is crossable to $C$. arietinum but with reduced fertility of the resulting hybrids and progenies; nevertheless, both are cross compatible with the cultigen and do not need in vitro interventions to produce hybrids. The tertiary gene pool consists of all the annual and perennial Cicer species that are not crossable to cultivated C. arietinum. All of the perennial Cicer species are considered to be in the tertiary gene pool as none of the species of this group are known to cross 
readily with the cultivated species and produce mature seeds (Mallikarjuna and Muehlbauer, unpublished).

Many of the Cicer species in the tertiary gene pool harbor important traits/genes necessary for the improvement of chickpea such as $H$. armigera resistance in C. judaicum, C. pinnatifidum and C. bijugum (13), Ascochyta blight resistance in C. judaicum, C. bijugum and C. pinnatifidum (12), Botrytis gray mold resistance (14), and drought tolerance (15). There are 34 perennial wild Cicer species that require very specific soil and environmental conditions for growth and reproduction. Traits of interest such as resistance to Ascochyta blight (16), H. armigera (17), Fusarium wilt (18), and drought tolerance (19) are present in this gene pool. Perennial Cicer species survive the severe frost conditions and resume their vegetative growth with the onset of summer in the USDA-ARS nursery located at Washington State University, Pullman, USA. All the perennial Cicer species have larger plant morphology compared to the annual Cicer species with robust vegetative growth. The flowers are larger with multiseeded fruits/pods. Desirable traits that chickpea would benefit from perennial Cicer are large and robust vegetative growth, large pods with multiple seeds, drought and cold tolerance, and disease and pest resistance.

It is now known that the barriers to hybridization between cultivated chickpea and Cicer species in the tertiary gene pool occur after zygote formation $(20,21)$. Fertilizations take place, but the zygote begins to abort by $3-5$ days after fertilization. Badami et al. (22) were able to postpone the abscission of pollinated pistils to 15-18 days by the application of growth regulators. This facilitated the growth of the hybrid embryo to early cotyledonary stage of development and being $0.5-1.0 \mathrm{~mm}$ in size (19).

Embryos of the size $0.5 \mathrm{~mm}$ or less did not grow directly on culture medium, while $0.3-0.4 \mathrm{~mm}$ size embryos responded well to specific growth hormones when cultured as in-ovulo embryo culture. Embryo response was maximum when zeatin $(\mathrm{Zn})$ was used in combination with indole-3-acetic acid (IAA) in in-ovulo embryo culture medium and was evident by the emergence of embryos from the ovule after 3-4 weeks (21). Similar response was not obtained when zeatin was replaced with other cytokinins, which reduced the number of responding embryos (Mallikarjuna, unpublished).

The best time to save the aborting seeds/ovules was when the hybrid embryo had reached its maximum growth and development, being at the cotyledonary stage of development, which was 15-18 days after pollination. If left longer on the plant, the pods turned yellow, indicating abortion of the hybrid seed.

Techniques such as in vitro culture to save aborting embryos from incompatible pollinations, multiplication of the hybrid shoots and their further growth, development of plants/shoots from somatic embryos, rooting in vitro grown shoots, grafting hybrid shoots on chickpea stocks, and induction of androgenesis 
1.1. Technical Comments from the hybrid plant's microspores will be discussed in the following paragraphs.

Hybrid shoots from the cross $C$. arietinum $\times$ C. pinnatifidum were pale yellow in color, and the scanning electron microscopic (SEM) studies showed that the chloroplasts were abnormal. Use of a cytokinin in culture medium in combination with light helped the conversion of leucoplastids to chloroplasts (22). Whereas hybrids between $C$. arietinum $\times C$. bijugum and between $C$. arietinum $\times C$. judaicum were green in color and albino shoots have not been observed. Hybrids between $C$ arietinum and C. pinnatifidum were fragile with the leaves resembling those of $C$. pinnatifidum. The color of the flower was pale violet, resembling the violet color of the male parent, and the pollen was $100 \%$ nonviable $(21)$.

Genotype of the cultivated chickpea, the female parent in the crossing program, was important for the success of the cross with respect to the number of hybrid ovules, in the size range of $2.5 \mathrm{~mm}$ or more, obtained and hybrid embryos responded. When chickpea cultivar ICCV 2 was crossed with C. pinnatifidum accession ICCW 37, although a larger number of pods were obtained than when crossed with cultivar ICCV 92318, the difference was larger with respect to the number of hybrid plants obtained. Many of the hybrid embryos from the crosses with ICCV 2 were small and abnormal even after ovule culture. A similar situation was observed in crosses with desi cultivars. Crosses with ICCV 6 did not set a large number of pods and ovules suitable for culture, and seedlings were not obtained. ICCV 10 set a large number of pods, and nine seedlings were obtained (21).

\section{Materials}

1. The hormone solution application to prevent flower abscission contains Gibberellic acid $\mathrm{A}_{3}$, naphthaleneacetic acid, and kinetin $\left(\mathrm{GA}_{3} 50 \mathrm{mg} / \mathrm{L}+\mathrm{NAA} 10 \mathrm{mg} / \mathrm{L}+\mathrm{Kn} 10 \mathrm{mg} / \mathrm{L}\right)$.

2. Sterilizing solution: a 30\% commercial bleach, Clorox solution.

3. Chickpea culture media: Murashige and Skoog's (MS) medium is generally used for chickpea tissue culture (Table 1). Modification of the MS medium known as the ML-6 medium (23) also works well for chickpea tissue culture. Major and minor salts (tissue culture grade) are prepared as $10 \times$ stocks and used to prepare medium.

4. Growth regulators: indole butyric acid (IBA), indole acetic acid (IAA), Gibberellin $\mathrm{A}_{3}$, benzyladenine, kinetin, and zeatin. All growth regulators are filter sterilized. 
Table 1

Media composition

\begin{tabular}{|c|c|c|c|c|c|}
\hline Nutrients $^{\mathrm{a}}$ & MS & ML-6 & Ovule culture & Shoot growth & Root induction ${ }^{b}$ \\
\hline \multicolumn{6}{|l|}{ Macronutrients } \\
\hline $\mathrm{NH}_{4} \mathrm{NO}_{3}$ & 1,650 & 1,000 & + & + & + \\
\hline $\mathrm{KNO}_{3}$ & 1,900 & 1,000 & + & + & + \\
\hline $\mathrm{MgSO}_{4} \cdot 7 \mathrm{H}_{2} \mathrm{O}$ & 370 & 170 & + & + & + \\
\hline $\mathrm{CaCl}_{2} \cdot 2 \mathrm{H}_{2} \mathrm{O}$ & 440 & 440 & + & + & + \\
\hline $\mathrm{KH}_{2} \mathrm{PO}_{4}$ & 170 & 170 & + & + & + \\
\hline $\mathrm{Na}_{2}$ EDTA & & & + & + & + \\
\hline $\mathrm{FeSO}_{4}$ & & & + & + & + \\
\hline \multicolumn{6}{|l|}{ Micronutrients } \\
\hline $\mathrm{MnSO}_{4} \cdot 4 \mathrm{H}_{2} \mathrm{O}$ & 22.3 & 0.0 & + & + & + \\
\hline $\mathrm{ZnSO}_{4} \cdot \mathrm{H}_{2} \mathrm{O}$ & 8.6 & 8.6 & + & + & + \\
\hline $\mathrm{H}_{3} \mathrm{BO}_{3}$ & 6.2 & 6.2 & + & + & + \\
\hline $\mathrm{KI}$ & 0.83 & 0.83 & + & + & + \\
\hline $\mathrm{Na}_{2} \mathrm{MoO}_{4} \cdot 2 \mathrm{H}_{2} \mathrm{O}$ & 0.25 & 0.25 & + & + & + \\
\hline $\mathrm{CoCl}_{2}^{2} \cdot 6 \mathrm{H}_{2} \mathrm{O}$ & 0.025 & 0.025 & + & + & + \\
\hline \multicolumn{6}{|l|}{ Vitamins } \\
\hline myo-Inositol & 100 & 100 & + & + & + \\
\hline Nicotinic acid & 0.5 & 0.5 & + & + & + \\
\hline Thiamine & 0.5 & 0.5 & + & + & + \\
\hline Glycine & 1.0 & 0.0 & + & + & + \\
\hline \multicolumn{6}{|l|}{ Growth regulators } \\
\hline IBA & & & & & 0.5 \\
\hline IAA & & & 0.25 & 0.5 & - \\
\hline $\mathrm{KN}$ & & & - & 2.0 & - \\
\hline Zeatin & & & 1.0 & - & - \\
\hline Agar (\%) & & & - & 0.68 & 0.7 \\
\hline Sucrose (\%) & & & 3 & 3 & 0.3 \\
\hline $\mathrm{pH}$ & & & $5.8 \pm 0.2$ & $5.8 \pm 0.2$ & $5.9 \pm 0.2$ \\
\hline
\end{tabular}

aAll ingredients are $\mathrm{mg} / \mathrm{L}$

${ }^{b}$ Half strength MS medium

5. Ovule culture medium (see Table 1) is a liquid medium devoid of agar.

6. Filter paper bridges for ovules (immature seeds) are prepared using Whatman No. 1 filter paper.

7. PVC tubing of $0.6 \mathrm{~cm}$ length and $3 \mathrm{~mm}$ in width was selected to hold the grafted shoot in place. 
8. Laboratory supplies: forceps, cotton swab, vials, polyethylene bags, scalpels, pots, and sand.

\section{Methods}

3.1. Cross Pollinations with Incompatible Cicer Species
3.2. Embryos Rescued from Interspecific Incompatible Crosses (Ovule Culture)
Plants used in the crossing program are cultivated under natural field conditions at $26-30^{\circ} \mathrm{C}$ maximum and $12-15^{\circ} \mathrm{C}$ minimum. These conditions give better pod set when used in the crossing program than grown in a glasshouse under similar temperature regimes. Wild species of Cicer take longer time to flower compared to cultivated chickpea. It is recommended to have staggered plantings of cultivated species to have continuous supply of flowers. Under ICRISAT, India conditions, wild species grown under additional light regime, after initial vegetative growth of about a month, induces profuse flowering.

Cross pollinations were carried out before $10.00 \mathrm{AM}$ in the chickpea growing season at ICRISAT, India (maximum $26-28^{\circ} \mathrm{C}$ and minimum $12-14^{\circ} \mathrm{C}$ ), although chickpea stigmas are receptive till late in the afternoon. It has been observed that the stigmas of cultivated chickpea remain receptive even at $35^{\circ} \mathrm{C}$ and till late in the afternoon.

1. Anthers were mechanically removed the previous evening from the buds chosen for pollination. All others buds at the node were removed to facilitate the growth of pollinated pistil.

2. Pollinations were carried out in the morning using fresh pollen from the male parent.

3. Soon after pollinations were carried out, cotton swab soaked with hormone solution containing Gibberellic acid $A_{3}$, Naphthaleneacetic acid, and kinetin $\left(\mathrm{GA}_{3} 50 \mathrm{mg} / \mathrm{L}+\mathrm{NAA}\right.$ $10 \mathrm{mg} / \mathrm{L}+\mathrm{Kn} 10 \mathrm{mg} / \mathrm{L})$ was wrapped around the base of the individual pistils to prevent flower abscission.

4. The process of hormone application was repeated for $1-3$ days depending upon the retention of flowers on the plant.

5. After 15-25 days of pollination, pods from cross pollinations, which began to turn yellow from green, were harvested and prepared for ovule culture (Fig. 1).

1. Immature pods from cross pollinations were collected from plants. Care was taken to allow immature seed to grow to its maximum, when the green pod wall began to turn pale shades of yellow (see Note 1).

2. Pods were surface-sterilized in a $30 \%$ commercial bleach (Clorox) for $15 \mathrm{~min}$, and the bleach was washed off by giving three to four washes with sterilized distilled water (see Note 2). 

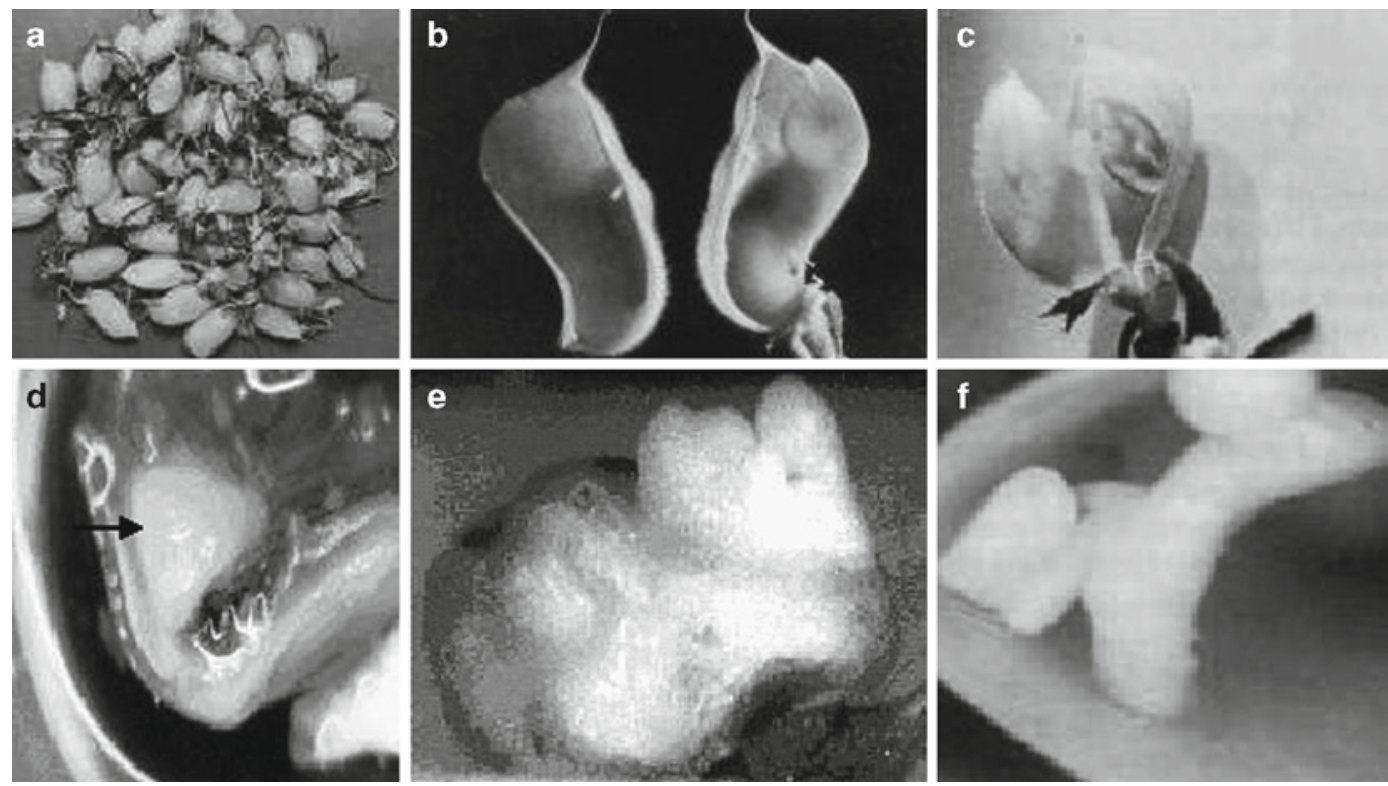

Fig. 1. Pod set, embryo abortion, and embryo rescue in chickpea wide crosses. (a) Pods from cross pollination $C$. arietinum $\times$ C. pinnatifidum. (b) Pod from cross pollination $(C$. arietinum $\times$ C. pinnatifidum), without the application of growth regulators, showing aborted seeds. (c) Pod from cross pollination $(C$. arietinum $\times C$. pinnatifidum) showing a $4.0 \mathrm{~mm}$ seed/ovule. (d) Cross section of a pod, obtained as a result of hormone aided pollination, from the cross $C$. arietinum $\times C$. pinnatifidum, showing the growth of the embryo (arrow). (e) Hybrid embryo emerging out of the cultured ovule. (f) Embryo dissected out of the ovule and cultured.

3. Liquid ovule culture medium was taken in small vials with filter paper bridges (see Notes 3 and 4; Table 1). It is cut as a $14 \mathrm{~cm}$ long and $3 \mathrm{~mm}$ width strip. The strip is longitudinally folded into half ( $1.5 \mathrm{~mm}$ strip) and made in the shape of an "M" with the outer borders longer than the central "V." Care is taken to see that the liquid medium does not cross the lower end of the shape "V."

4. Ovules (immature seeds) are carefully dissected out of the pods with the placental region still attached to the ovule and cultured on filter paper bridges. Care should be taken not to submerge the ovules in the liquid medium, which consisted of MS or ML- 6 basal salts $+3 \%$ sucrose $+\mathrm{IAA}(0.25 \mathrm{mg} / \mathrm{L})+\mathrm{Zn}$ $(1.0 \mathrm{mg} / \mathrm{L})$ (Table 1 and also see Notes 5 and 6). Zeatin and IAA used is always filter-sterilized.

5. After 3 weeks of culture, ovules were transferred to fresh ovule culture medium till the embryos emerged out of the ovules (see Note 7).

6. Embryos that emerged out of the ovule were transferred to shoot growth medium, where the source of cytokinin was kinetin instead of zeatin.

7. Well-grown shoots were transferred to root induction medium, which consists of $1 / 2$ strength MS basal salts, $1.5 \%$ 

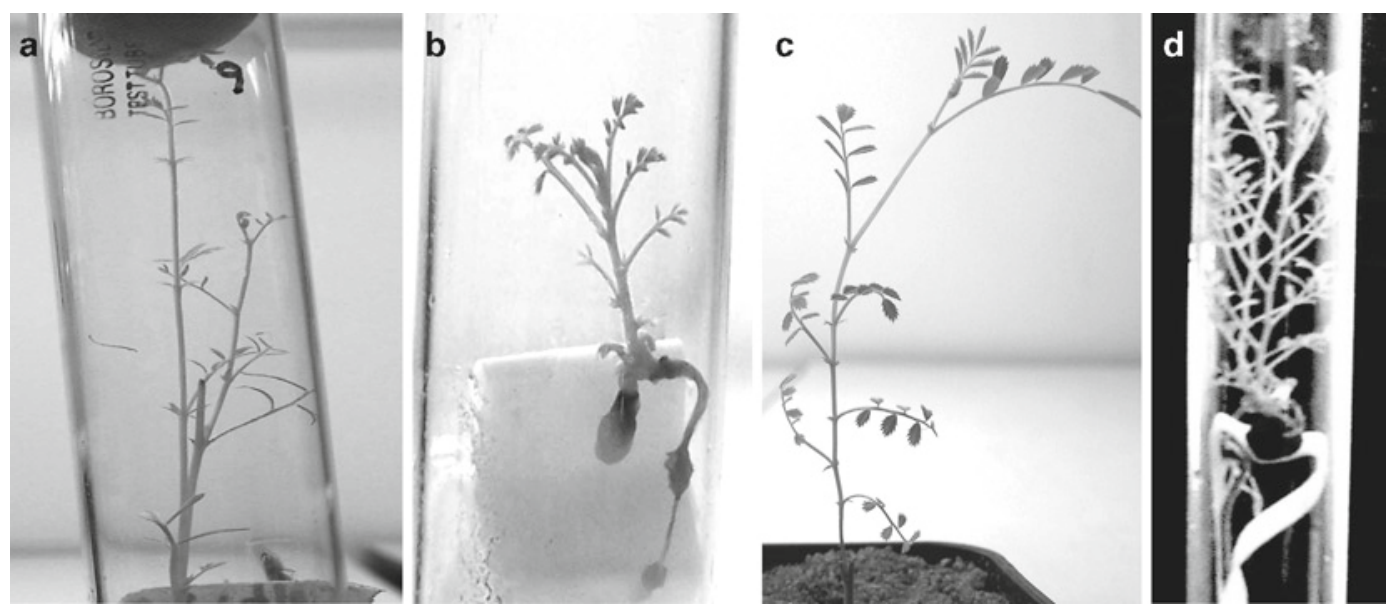

Fig. 2. Hybrid plants obtained through ovule culture in vitro. (a) $C$. arietinum $\times$ C. judaicum seedling. (b) $C$. arietinum $\times C$. bijugum seedling. (c) C. reticulatum $\times$ C. pinnatifidum seedling. (d) $C$. arietinum $\times$ C. pinnatifidum seedling.

\subsection{Shoot}

\section{Multiplication In Vitro}

3.4. Somatic Embryos from Immature Cotyledons sucrose, $0.7 \%$ agar, with IBA $0.5 \mathrm{mg} / \mathrm{L}$. Alternatively, shoots are grafted to cultivated chickpea stocks (see Note 8 ).

8. After a pulse treatment of 15 days on the rooting medium, shoots were transferred to the basal MS medium to induce roots on shoots.

9. Rooted shoots were transferred to pots with sieved sand and watered with sterilized tap water (see Note 9; Fig. 2).

10. It was important to maintain high humidity by covering the transferred plants with a polythene bag.

1. Shoot buds were produced in clumps when embryos are transferred to embryo/shoot growth medium.

2 . Individual shoots that were more than $2-3 \mathrm{~cm}$ long are separated from the clumps and transferred to the shoot growth medium, which was same as embryo growth medium (Table 1).

3. Shoots that grew further were transferred to root induction medium or grafted to cultivated chickpea stocks.

1. Immature pods of either kabuli or desi chickpea are surface sterilized with 30\% Clorox (commercial bleach).

2. Pods are washed with sterilized distilled water for four to five times to remove traces of Clorox (see Note 10).

3. Immature cotyledons (4-5 $\mathrm{mm}$ in size) devoid of embryo axis are isolated in a sterilized Petri dish.

4. Medium for culture $[\mathrm{MS}+3.0 \%$ sucrose $+\mathrm{Zn}(14.0 \mu \mathrm{M} / \mathrm{L})+\mathrm{IAA}$ $(5.0 \mu \mathrm{M} / \mathrm{L})$ at $\mathrm{pH} 5.8]$ is poured into sterile Petri dishes. 
5. Cotyledons are cultured on the medium with their adaxial surface up, against the medium.

6. For further growth, somatic embryos were transferred to MS medium with $2 \mathrm{mg} / \mathrm{L} \mathrm{BAP}$ and $0.5 \mathrm{mg} / \mathrm{L}$ IAA (see Note 11).

7. Those embryos, which have grown into seedlings and without good root systems, were transferred to the rooting medium mentioned above (see Note 12).

8. Well-grown shoots were transferred to fine sand initially and later to soil: sand: farm yard manure (1:1:1) (see Note 13).

3.5. Grafting Hybrid Shoots to Chickpea Stocks
Transfer of hybrid shoots to soil is a critical step for the success of crosses with incompatible annual Cicer species. Although percent response with respect to the number of pollinations made and the number of hybrid plants obtained are low (21), techniques to produce hybrid shoots are in place when chickpea is crossed with C. pinnatifidum, C. bijugum, and C. judaicum. It is possible to multiply hybrid shoots in vitro by transferring the hybrid shoot buds to $0.7 \%$ agar solidified MS medium with $3 \%$ sucrose, $0.5 \mathrm{mg} / \mathrm{L} \mathrm{IAA}$, and $2.0 \mathrm{mg} / \mathrm{L} \mathrm{KN}$ at $\mathrm{pH} 5.8$ (Table 1). Shoots can be rooted on full strength or $1 / 2$ MS basal medium with $1.5 \%$ sucrose, $0.5 \mathrm{mg} / \mathrm{L}$ IBA (Table 1 ). In most of the cases, the roots were stunted, and hence very few shoots survived the transfer to soil. To overcome the problem of rooting hybrid shoots, an alternative method of grafting hybrid shoots to chickpea stocks was standardized (see Fig. 3; (24)).

1. 15 days old chickpea seedlings were used as stocks.

2. The hybrid shoots to be grafted (scion), which were $3 \mathrm{~cm}$ or more, are cut into a "V" shape.

3. The Root stock plants are cut just above the base of the stem, about $2-3 \mathrm{~cm}$ from the soil. All axillary buds are removed to prevent the growth of axillary shoots.

4. A $0.5 \mathrm{~cm}$ PVC tubing whose diameter is slightly more than that of the stem is slid on the blunt end of the stem. It is essential to see that the tubing selected is flexible and can expand marginally.

5. The slit is made on the blunt send of the stem, dividing it into two equal parts.

6. The scion is inserted into the slit and secured in place with the help of the rubber tubing.

7. When the grafts had established, the tubing was slit longitudinally to free the grafted region.

8. The pot is covered with a plastic bag to maintain high humidity (see Note 14). 

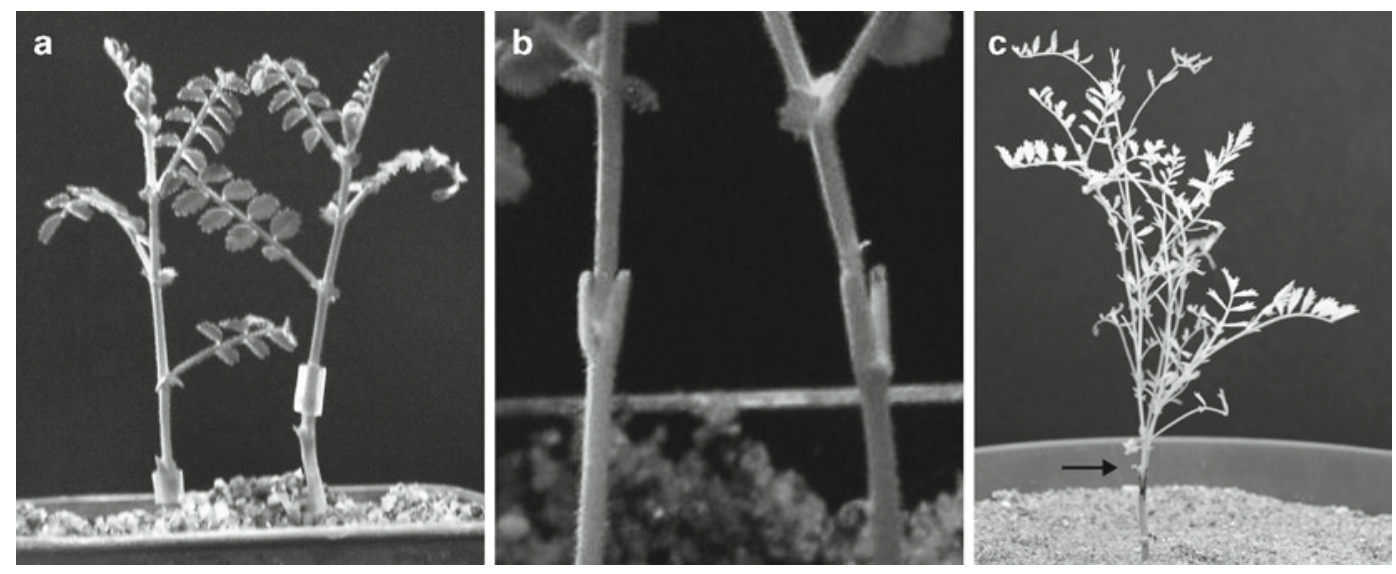

Fig. 3. Grafting technique in chickpea. (a) $C$. arietinum plant grafted with $C$. arietinum $\times C$. bijugum hybrid shoot. Note the rubber tubing holding the grafts. (b) After 3-4 weeks, the rubber tubes have been removed to facilitate further growth. (c) The graft $(C$. arietinum $\times$ C. pinnatifidum) growing well. Arrow points to the region of the graft.

\subsection{Development of Multicellular Microspores}

Development of haploid plants from anther/microspore culture is now possible (25). It is also possible to get multicellular microspores from wide crosses. Mallikarjuna and Jadhav (24) and Mallikarjuna et al. (26) demonstrated that the hybrid between chickpea and C. pinnatifidum gave rise to flower buds with multicellular microspores in large numbers with divisions in all the microspores in some plants. As the critical step of induction of androgenesis in chickpea microspores had taken place, culturing such microspores may give rise to high frequency of haploid plants.

1. Hybrid plants from the cross C. arietinum $\times$ C. pinnatifidum need to be maintained in a growth chamber with $70 \%$ relative humidity (see Note 14).

2. Plants are watered with either de-ionized or drinking quality water with $1 \mathrm{mg} / \mathrm{L}$ zeatin. Inclusion of zeatin induces floral buds on the plants (see Note 15).

3. The buds/flower are fragile, and many of the buds have anthers with multicellular microspores with the number of cells ranging from 4 to more than 10 (see Note 16).

4. The authors have not cultured such microspores to obtain haploid plants.

\section{Notes}

1. Application of growth regulator combination, specified for chickpea wide crosses with any of the incompatible species is mandatory. Without its application, ovules begin to abort from third day after pollination (21). 
2. Surface sterilization in alcohol or even brief wash in alcohol is not advisable as it reduces the number of responding ovules.

3. Adding filter sterilized IAA and zeatin into the ovule culture medium gives better response.

4. Embryos do not respond when cultured on semisolid medium.

5. Percent response is better when cultured with the placental region attached to the ovule.

6. Ovules respond only when cultured on the liquid medium with zeatin as the source of cytokinin. Ovules do not respond when zeatin in the culture medium is replaced with either kinetin or benzyl amino purine.

7. A second transfer of the ovules to the ovule culture medium increases the number of responding ovules.

8. Although a method to root shoots in vitro has been developed, it is not efficient, which is reflected in the percent successful transfer of rooted shoots to soil. Alternatively, grafting the shoots to chickpea stocks is very successful $(>90 \%)$.

9. In vitro rooting is not very efficient for chickpea plants regenerated through multiple subcultures in vitro.

10. Traces of Clorox on the pod wall can reduce percentage of responding embryos.

11. Embryos cluster all around the cotyledons. Culturing clumps of embryos on the shoot growth medium enhances the growth of normal embryos. It is to be noted that many of the somatic embryos are abnormal without the shoot or root axis.

12. It is a straight forward process to root chickpea shoots in vitro, which have not been subcultured in vitro. Every subculture reduces rooting efficiency and by third subculture very few shoots root. Roots on the shoots from three or more subcultures are not only scanty but are unhealthy and do not withstand the transfer to soil. This may be one of the reasons why hybrid shoots, which have undergone subculture/s, do not root well on the root induction medium.

13. Hybrid shoots regenerated from immature aborting embryos are fragile and do not withstand the transfer to soil directly. They are transferred to pots with sand initially. Later, they are transferred to soil.

14. Even though the plants are maintained in an incubator at $25^{\circ} \mathrm{C}$ and high relative humidity, covering them with a polythene cover helps the grafts grow faster.

15. Interspecific hybrid between $C$. arietinum $\times C$. pinnatifidum starts flowering when zeatin $1.0 \mathrm{mg} / \mathrm{L}$ is added to the nutrient solution or the water, which is used to water the hybrid plants (24). 
16. Multicellular microspores are starting material to obtain haploid plants. Although dihaploid plants are reported for chickpea, another mode of obtaining the induction of androgenesis is by wide crosses.

\section{References}

1. Williams PC, Singh U (1987) Nutritional quality and the evaluation of quality in breeding programme. In: Saxena MC, Singh KB (eds) The chickpea. C.A.B. International, Wallingford, UK, pp 125-130

2. Abbo S, Molina C, Jungmann R, Grusak M, Berkovitch Z, Reifen R, Kahl G, Winter P, Reifen R (2005) Quantitative trait loci governing carotenoid concentration and weight in seeds of chickpea (Cicer arietinum L.). Theor Appl Genet 111:185-195

3. Kerem Z, Gopher A, Lev-Yadun S, Weinberg $\mathrm{P}$, Abbo S (2007) Chickpea domestication in the Neolithic Levant through the nutritional perspective. J Archaeol Sci 34:1289-1293

4. Nene YL, Haware MP (1980) Screening chickpea for resistance to wilt. Plant Dis 64:379-380

5. Reed W, Cardona C, Sithanantham S, Lateef SS (1987) Chickpea insect pests and their control. In: Saxena MC, Singh KB (eds) The chickpea. C.A.B. International, Wallingford, UK, pp 283-318

6. Collard BCY, Pang ECK, Ades PK, Taylor PWJ (2003) Preliminary investigation of QTLs associated with seedling resistance to Ascochyta blight from Cicer echinopsermum, a wild relative of chickpea. Theor Appl Genet 107:719-729

7. Ramgopal D (2006) Characterization and evaluation of annual wild Cicer species and study the transfer of Botrytis gray mold and Ascochyta blight resistance from Cicer echinopsermum into cultivated species. Ph.D. Thesis, Acharya N.G. Ranga Agricultural University, Rajendra Nagar, Hyderabad, India

8. Mallikarjuna N, Sharma HC, Upadhyaya HD (2007) Exploitation of wild relatives of pigeonpea and chickpea for resistance to Helicoverpa armigera. SAT e-Journal 3:4-7

9. Malhotra RS, Singh KB, Di Vito M, Greco N, Saxena MC (2002) Registration of ILC 10765 and ILC 10766 chickpea germplasm lines resistant to cyst nematode. Crop Sci 42:1756

10. Singh KB, Ocampo B (1997) Exploitation of wild Cicer species for the yield improvement of chickpea. Theor Appl Genet 95:418-423
11. Harlan J, de Wet J (1971) Towards a rational classification of cultivated plants. Taxon 20:509-517

12. van der Maesen LJG, Maxted N, Javadi F, Coles S, Davies AMR (2007) Taxonomy of the genus Cicer revisited. In: Yadav SS, Redden B, Chen W, Sharma B (eds) Chickpea breeding and management. C.A.B. International, Wallingford, UK, pp 14-46

13. Sharma HC, Pampapathy G, Lanka SK, Ridsdill-Smith TJ (2005) Antibiosis mechanism of resistance to pod borer, Helicoverpa armigera in wild relatives of chickpea. Euphytica 142:107-117

14. Pande S, Ramgopal D, Kishore GK, Mallikarjuna N, Sharma $M$, Pathak $M$, Narayana Rao J (2006) Evaluation of wild Cicer species for resistance to Ascochyta blight and Botrytis gray mold in controlled environment at ICRISAT, Patancheru, India. ICPN $13: 25-26$

15. Bhattarai T, Fettig S (2005) Isolation and characterization of a dehydrin gene from Cicer pinnatifidum, a drought-resistant wild relative of chickpea. Physiol Plant 123:452-458

16. Muehlbauer FJ, Kaiser WJ, Simon CJ (1994) Potential for wild species in cool season food legume breeding. Euphytica 73:109-114

17. Sharma HC, Bhagwat MP, Pampapathy G, Sharma JP, Ridsdill-Smith TJ (2006) Perennial wild Cicer relatives of chickpea as potential sources of resistance to Helicoverpa armigera. Genet Resour Crop Evol 53:131-138

18. Kaiser WJ, Alcala-Jimenez AR, Hervas-Vargas A, Trapero-cacas JL, Jimenez-Diaz RM (1994) Screening of wild Cicer species for resistance to races 0 and 5 of Fusarium oxysporum f. sp. ciceris. Plant Dis 78:962-967

19. Toker C, Canci H, Yildirim T (2007) Evaluation of perennial wild Cicer species for drought resistance. Genet Resour Crop Evol 54:1781-1786

20. Ahmad F, Slinkard AE, Scoles GJ (1988) Investigations into the barrier(s) to interspecific hybridization between Cicer arietinum $\mathrm{L}$. and eight other annual Cicer species. Plant Breed 100:193-198

21. Mallikarjuna N (1999) Ovule and embryo culture to obtain hybrids from interspecific 
incompatible pollinations in chickpea. Euphytica 110:1-6

22. Badami PS, Mallikarjuna N, Moss JP (1997) Interspecific hybridization between Cicer arietinum and C. pinnatifidum. Plant Breed 116:393-395

23. Kumar AS, Gamborg OL, Nabors MW (1988) Plant regeneration from cell suspension cultures of Vigna aconitifolia. Plant Cell Rep 7:138-141

24. Mallikarjuna N, Jadhav DR(2008) Techniques to produce hybrid between Cicer arietinum
L. $\times$ C. pinnatifidum Jaub. Indian J Genet 68:1-8

25. Grewal RK, Lulsdorf M, Croser J, Ochatt S, Vandenberg A, Warkentin TD (2009) Doubled-haploid production in chickpea (Cicer arietinum $\mathrm{L}$.): role of stress treatments. Plant Cell Rep 28:1289-1299

26. Mallikarjuna N, Jadhav DJ, Clarke H, Coyne C, Muehlbauer F (2005) Induction of androgenesis as a consequence of wide crossing in chickpea. Int Chickpea Pigeonpea Newsl $12: 12-15$ 